\title{
Systemic infection modifies the neuroinflammatory response in late stage Alzheimer's disease
}

\author{
Sonja Rakic, Yat M. A. Hung ${ }^{1}$, Matthew Smith', Denise So ${ }^{1}$, Hannah M. Tayler², William Varney ${ }^{1}$, Joe Wild ${ }^{1}$,
} Scott Harris ${ }^{3}$, Clive Holmes ${ }^{1,4}$, Seth Love ${ }^{2}$, William Stewart ${ }^{5,6}$, James A. R. Nicoll ${ }^{1,7}$ and Delphine Boche ${ }^{1 *}$ (D)

\begin{abstract}
Clinical studies indicate that systemic infections accelerate cognitive decline in Alzheimer's disease. Animal models suggest that this may be due to enhanced pro-inflammatory changes in the brain. We have performed a postmortem human study to determine whether systemic infection modifies the neuropathology and in particular, neuroinflammation, in the late-stage of the disease.

Sections of cerebral cortex and underlying white matter from controls and Alzheimer's patients who died with or without a terminal systemic infection were immunolabelled and quantified for: (i) $A \beta$ and phosphorylated-tau; (ii) the inflammation-related proteins Iba1, CD68, HLA-DR, FcyRs (CD64, CD32a, CD32b, CD16), CHIL3L1, IL4R and CCR2; and (iii) T-cell marker CD3. In Alzheimer's disease, the synaptic proteins synaptophysin and PSD-95 were quantified by ELISA, and the inflammatory proteins and mRNAs by MesoScale Discovery Multiplex Assays and qPCR, respectively. Systemic infection in Alzheimer's disease was associated with decreased CD16 ( $p=0.027$, grey matter) and CD68 ( $p=0.015$, white matter); increased CD64 ( $p=0.017$, white matter) as well as increased protein expression of IL6 ( $p=0$. 047) and decreased IL5 ( $p=0.007), I L 7(p=0.002)$, IL12/IL23p40 ( $p=0.001), I L 15(p=0.008), I L 16(p<0.001)$ and IL17A $(p<0.001)$. Increased expression of anti-inflammatory genes CHI3L1 $(p=0.012)$ and IL $4 R(p=0.004)$ were detected in this group. T-cell recruitment to the brain was reduced when systemic infection was present. However, exposure to systemic infection did not modify the pathology. In Alzheimer's disease, CD68 ( $p=0.026)$, CD64 ( $p=0.002)$, CHI3L1 $(p=0.016)$, IL4R $(p=0.005)$ and CCR2 $(p=0.010)$ were increased independently of systemic infection.

Our findings suggest that systemic infections modify neuroinflammatory processes in Alzheimer's disease. However, rather than promoting pro-inflammatory changes, as observed in experimental models, they seem to promote an anti-inflammatory, potentially immunosuppressive, environment in the human brain.
\end{abstract}

Keywords: Alzheimer's disease, Systemic infection, Neuroinflammation, Human brain, Microglia

\section{Introduction}

Systemic infections lead to the development of "sickness behaviour", clinical features of which include fever, depression, apathy, self-reported ill health and attentional deficits [18]. At least in animal models this is, in part, mediated by the transient production of pro-inflammatory cytokines by microglia, in turn activated by cytokines and other inflammatory mediators generated by peripheral immune cells $[17,18]$. In humans, the clinical features of sickness

\footnotetext{
* Correspondence: d.boche@soton.ac.uk

${ }^{1}$ Clinical Neurosciences, Clinical and Experimental Sciences Academic Unit, Faculty of Medicine, University of Southampton, Southampton, UK Full list of author information is available at the end of the article
}

behaviour are usually considered benign and transitory. However, animal studies have shown that, when microglia are "primed" by early neurodegeneration, systemic infection can switch the central innate immune response from a hybrid of pro- and anti-inflammatory phenotypes to a more tissue-damaging environment, with enhanced and prolonged pro-inflammatory cytokine synthesis in the brain, symptoms of sickness behaviour, and increased neuronal death $[15,16]$.

Microglia are highly plastic and dynamic cells [47] that adapt their behaviour and morphology to adjust to their environment, adopting different profiles and morphologies

(c) The Author(s). 2018 Open Access This article is distributed under the terms of the Creative Commons Attribution 4.0 International License (http://creativecommons.org/licenses/by/4.0/), which permits unrestricted use, distribution, and reproduction in any medium, provided you give appropriate credit to the original author(s) and the source, provide a link to the Creative Commons license, and indicate if changes were made. The Creative Commons Public Domain Dedication waiver (http://creativecommons.org/publicdomain/zero/1.0/) applies to the data made available in this article, unless otherwise stated. 
$[8,25]$. It was proposed that in patients with neurodegenerative disease, systemic infection would exacerbate symptoms of the disease, increase tissue injury and accelerate disease progression [54]. In the absence of neurodegenerative disease, post-mortem studies have shown that systemic infection is associated with increased activation of vascular endothelial cells, perivascular macrophages [65] and microglia $[38,61]$. In prospective clinical studies of people with Alzheimer's disease (AD), systemic infection with raised peripheral pro-inflammatory cytokines is associated with a marked increase in the rate of cognitive decline and in the neuropsychiatric features of sickness behaviour [29, 30]. This supports the hypothesis that microglia in the diseased brain, in a relatively benign but primed inflammatory state [55], may be activated by signalling molecules from systemic infection [59], to produce cytokines and other molecules that promote neuronal dysfunction and degeneration.

To explore the effects of systemic infection on the human $\mathrm{AD}$ brain, we have conducted a post-mortem study in which Alzheimer's cases were selected on the basis of the presence or absence of systemic infection at the time of death. We investigated whether systemic infection modifies the neuroinflammatory environment and thus the microglial profile, and assessed the potential consequences on $\mathrm{AD}$-associated pathologies.

\section{Materials and methods \\ Cases}

Autopsy-acquired brain tissue from 108 donors was sourced from the South West Dementia Brain Bank (University of Bristol) and BRAIN UK (Queen Elizabeth University Hospital, Glasgow). Clinical history as included in post-mortem reports and information on the death certificate was used to subdivide cases according to whether systemic infection was or was not recorded as cause of death into four subgroups: cognitive and neuropathological controls (Ctrl), who died without systemic infection (Ctrl-, $n=24$ ) or with systemic infection (Ctrl+, $n=16$ ); and AD patients, who died without systemic infection (AD-, $n=28$ ) or with systemic infection (AD+, $n=40)$. Alzheimer's cases had a clinical diagnosis of AD made during life and satisfied post-mortem neuropathological consensus criteria for $\mathrm{AD}$ [31] without having any other significant brain pathologies such as stroke, primary or metastatic tumour, or traumatic lesions. The causes of death in the control and AD groups without systemic infection included cardiovascular disease and non-brain tumours. In the control and AD groups with systemic infection, death was attributed in most cases to bronchopneumonia and urinary tract infection. The characteristics of the groups are presented in Table 1.

The inferior parietal lobe (Brodmann area 40), an area of cerebrum typically affected by AD pathology [45], was investigated in all cases. Formalin-fixed paraffin embedded tissue was used for the immunodetection of neuropathological and neuroinflammatory markers in the control and AD groups. Fresh frozen tissue available only for the AD groups with and without systemic infection and selected on a $\mathrm{pH}>6.0$ to ensure RNA integrity $[4,56]$, was used for detection of synaptic proteins by ELISA, and for detection of inflammation-related proteins and mRNA by MesoScale Discovery (MSD) multiplex assays and quantitative (q) PCR.

\section{Immunohistochemistry}

Immunohistochemistry was performed on $4 \mu \mathrm{m}$ paraffin sections in several separate batches, with each batch containing cases from all groups (Ctrl-, Ctrl+, AD-, AD+) to ensure comparability of immunolabelling. All experiments included a negative control slide incubated in buffer with no primary antibody, and a positive control slide containing a specific tissue type known to express the protein of interest (e.g. tonsil). Details of the primary antibodies including immune functions and pre-treatments are presented in Additional file 1: Table S1. Biotinylated secondary antibodies rabbit anti-goat and swine anti-rabbit were from Dako (Glostrup, Denmark) and goat anti-mouse from Vector Laboratories (Peterborough, UK). Bound antibodies were visualized using the avidin-biotin-peroxidase complex method (Vectastain Elite, Vector Laboratories) with 3,3'-diaminobenzidine as chromogen and $0.05 \%$ hydrogen peroxide as substrate (Vector Laboratories). All sections were counterstained with haematoxylin, then dehydrated before mounting in DePeX (VWR International, Lutterwort, UK).

\section{Quantification}

Quantification was blinded to the case designation and performed separately on the grey matter and white matter in the same sulcus of the inferior parietal lobule for all cases, as determined by an experienced neuropathologist (JARN). For each case, 30 images of grey matter were acquired by the Olympus dotSlide virtual microscopy system under a $\times 20$ objective. The images were obtained in a zigzag sequence to ensure sampling of all six cortical layers as previously published [44, 74]. An additional 30 images were obtained of the subcortical white matter. Quantitative image analysis was carried out using ImageJ (version 1.49u, Wayne Rasband, NIH, USA). For each antibody, a specific threshold was determined to quantify the area fraction of each image labelled by the antibody and expressed as protein load (\%), and the mean value was calculated for each case for each antibody.

For $\mathrm{T}$ cells, semi-quantitative analysis was performed manually and based on assessment of the whole section under a $\times 10$ objective. CD3+ T-cells were identified as present or absent in the vasculature and parenchyma of 
Table 1 Demographic, clinical and post-mortem characteristics of controls and Alzheimer's cases

\begin{tabular}{|c|c|c|c|c|}
\hline Cases & $\begin{array}{l}\text { Ctrl- } \\
(n=24)\end{array}$ & $\begin{array}{l}\text { Ctrl+ } \\
(n=16)\end{array}$ & $\begin{array}{l}\text { AD- } \\
(n=28)\end{array}$ & $\begin{array}{l}\mathrm{AD}+ \\
(n=40)\end{array}$ \\
\hline Gender & 12F:12M & 7F:9M & 16F:12M & 25F:15M \\
\hline Age of Death (years, mean \pm SD) & $80.4 \pm 10.4$ & $82.1 \pm 9.5$ & $81.1 \pm 6.1$ & $82 \pm 7.4$ \\
\hline Age of $A D$ onset (years, mean $\pm S D$ ) & $\mathrm{n} / \mathrm{a}$ & $\mathrm{n} / \mathrm{a}$ & $72.7 \pm 7.7$ & $74.3 \pm 8.9$ \\
\hline Duration of AD (years, mean $\pm S D$ ) & $\mathrm{n} / \mathrm{a}$ & $\mathrm{n} / \mathrm{a}$ & $8.4 \pm 4.3$ & $7.7 \pm 4.0$ \\
\hline \multirow[t]{3}{*}{ Braak Stage } & 0-II: 18 & 0-II: 11 & 0-II: 0 & 0-II: 0 \\
\hline & IIIIIV: 2 & IIIIIV: 2 & IIIIIV: 6 & IIIIIV: 6 \\
\hline & V-VI: 0 & V-VI: 0 & V-Vl: 22 & V-Vl: 34 \\
\hline \multicolumn{5}{|l|}{ Cause of death } \\
\hline Cardiovascular disease & 20/24 (83.3\%) & & $7 / 28(25 \%)$ & \\
\hline Non-brain tumour & $2 / 24(8.3 \%)$ & & $5 / 28(17.9 \%)$ & \\
\hline Other & ${ }^{\mathrm{a}} 2 / 24(8.3 \%)$ & ${ }^{a} 2 / 16(12.5 \%)$ & $\mathrm{b}_{16 / 28}(57.1 \%)$ & $a_{3 / 40}(7.5 \%)$ \\
\hline Bronchopneumonia & & $12 / 16(75 \%)$ & & $32 / 40(80 \%)$ \\
\hline Urinary Tract Infection & & $2 / 16(12.5 \%)$ & & $5 / 40(12.5 \%)$ \\
\hline \multicolumn{5}{|l|}{ APOE genotype } \\
\hline$\varepsilon 4 /-$ & $2 / 19(10.5 \%)$ & $2 / 10(20 \%)$ & 9/23 (39.1\%) & $15 / 36(41.7 \%)$ \\
\hline$\varepsilon 4 / \varepsilon 4$ & $1 / 19(5.3 \%)$ & 0/10 (0\%) & $5 / 23(21.7 \%)$ & $8 / 36(22.2 \%)$ \\
\hline Post-mortem delay (hours, mean \pm SD) & $34.6 \pm 18.5$ & $50.1 \pm 27.4$ & $37.8 \pm 26.8$ & $48.2 \pm 23.3$ \\
\hline $\mathrm{pH}$ & $\mathrm{n} / \mathrm{a}$ & $\mathrm{n} / \mathrm{a}$ & $6.1 \pm 0.4$ & $6.1 \pm 0.3$ \\
\hline
\end{tabular}

Ctrl neurologically/cognitively normal controls, $A D$ Alzheimer's disease, - died without systemic infection, + died with systemic infection, $F$ female, $M$ male, $R I N$ RNA integrity number, $n / a$ not-applicable, $S D$ standard deviation

Braak staging and $A P O E$ genotyping were not available for all cases

other cause of death included: ${ }^{a}$ bowel obstruction, ruptured abdominal aortic aneurysm, fall (fractured femur); ${ }^{b}$ Alzheimer's disease

the grey and white matter. Subsequent analysis was based on the percentage of cases with $\mathrm{T}$ cells present or absent in each subgroup.

\section{ELISA}

ELISA was carried out to quantify the presynaptic protein synaptophysin (SYP), postsynaptic density protein 95 (PSD95), and neuron-specific enolase (NSE) - a neuronal marker used to control for variation in neuronal content between samples. The ratio of synaptophysin to PSD95 was calculated as an indicator of selective pre- or post-synaptic loss. $100 \mathrm{mg}$ of fresh frozen grey matter from AD cases $(n=67)$ was homogenised in lysis buffer at a tissue concentration of $20 \% w / v$ [66] and total protein measured by Pierce Coomassie (Bradford) Protein Assay Kit (Thermo Fisher Scientific, Waltham, USA). Non-specific binding was blocked with blocking buffer (1\% BSA-PBS). All measurements were corrected for total protein concentration. SYP and PSD95 values were subsequently adjusted for NSE concentration.

\section{SYP and NSE measurements}

SYP and NSE were measured by sandwich ELISA and PSD95 by indirect ELISA [52, 62]. The capture antibody, SYP (Abcam, Cambridge, UK) or NSE (Enzo Life Sciences, Exeter, UK), was diluted 1:1000 in coating buffer and the wells preincubated overnight at $4{ }^{\circ} \mathrm{C}$. Blocking buffer (1\% BSA-PBS) was added for $1 \mathrm{~h}$ followed by the load in duplicate of either serial 5 -fold dilutions of recombinant NSE protein $(0.008-5 \mu \mathrm{g} / \mathrm{ml}$; Abcam) to generate a standard curve, or 2-fold dilutions of recombinant SYP protein $(0.34-5.5 \mu \mathrm{g} / \mathrm{ml}$; Abnova, Taipei City, Taiwan), homogenates at a 1:10 or blanks. Two hours later, peroxidase-labelled, mouse monoclonal anti-NSE (Abcam) or biotinylated anti-mouse IgG for SYP detection (Vector Laboratories), was added and incubated in the dark for $2 \mathrm{~h}$.

\section{Measurement of PSD95}

Homogenate samples were diluted 1:20 and incubated in duplicate alongside blanks and a standard curve, comprising 3-fold dilutions of recombinant PSD95 protein (3.75-910.1 ng/ml; Abnova), for $2 \mathrm{~h}$ at $26^{\circ} \mathrm{C}$. Primary antibody (PSD95, clone 7E3-1B8, Sigma Aldrich, Gillingham, UK) diluted to $1: 3000$ was incubated for $2 \mathrm{~h}$ at $26{ }^{\circ} \mathrm{C}$ followed by the addition of a secondary antibody (HRP-labelled anti-mouse IgG; Vector Laboratories). The final stage of each ELISA involved the addition of a peroxidase substrate (R\&D Systems, Minneapolis, USA).

For all of the ELISAs, absorbance was read at $450 \mathrm{~nm}$ in a multi-mode microplate reader (FLUOstar OPTIMA, BMG Labtech) and absolute protein levels $(\mu \mathrm{g} / \mathrm{ml})$ were 
determined by interpolation against the relevant standard curve.

\section{MesoScale discovery multiplex assay}

Inflammatory proteins were measured on the V-Plex MSD electrochemiluminescence multi-spot assay platform (MesoScale Diagnostics, Rockville USA).100 mg of fresh frozen grey matter from $\mathrm{AD}$ cases $(n=67)$ was homogenised at a tissue concentration of $20 \% \mathrm{w} / v$ in RIPA lysis buffer (Thermo Fisher Scientific) by use of a handheld homogeniser (Thermo Fisher Scientific); the buffer was supplemented with protease inhibitors (Complete Mini, Sigma Aldrich) and phosphatase inhibitors (Thermo Fisher Scientific). Total protein concentration in the supernatant was measured by BCA Protein Assay Kit (Thermo Fisher Scientific). 12.5 $\mu \mathrm{l}$ of brain homogenate (1:4 dilution) was used for each assay according to the manufacturer's protocol. The following V-PLEX human biomarker 40-PLEX kits were used: pro-inflammatory panel 1 , cytokine panel 1 and vascular injury panel 2. Each plate was imaged on the Meso QuickplexSQ120 (MesoScale Discovery) according to manufacturers' instructions for 384-well plates to obtain absolute protein levels (pg/ml). Frozen blocks from 4 controls and 2 multiple sclerosis brains containing chronic inactive, acute and chronic active lesions were used as negative and positive controls, respectively.

\section{qPCR}

Inflammatory gene expression was determined by qPCR. mRNA was isolated in TRI-Reagent (Thermo Fisher Scientific) from $100 \mathrm{mg}$ of fresh frozen grey matter from Alzheimer's cases $(n=67)$. Reverse transcription (RT) was performed using the high capacity cDNA reverse transcription kit (Thermo Fisher Scientific). Gene expression was analysed using TaqMan gene expression assays (Thermo Fisher Scientific; Additional file 1: Table S2) and TaqMan universal PCR master mix in a $7900 \mathrm{HT}$ fast qPCR system machine (Thermo Fisher Scientific). RT and qPCR were performed as previously described [43, 52]. The same control and multiple sclerosis tissue as for the MSD protocol was utilized.

Data were extracted using SDS version 2.13 software (Thermo Fisher Scientific). The mRNA levels of the inflammatory markers were calibrated against GAPDH mRNA and the fold difference between groups was calculated by the $2^{-\Delta \Delta \mathrm{Ct}}$ method.

\section{Statistical analysis}

For all immunohistochemistry and assay data, the normality of distribution across each group was assessed by examination of quantile-quantile plots (not shown). Immunohistochemistry: The means within each group were compared by two-way ANOVA to assess the effect of
Alzheimer's disease or/and systemic infection on different proteins in the grey and white matter. Data were presented as mean \pm standard deviation (SD). If an "Alzheimer's disease" or "infection" effect was observed on its own, the contrast model was applied. If an interaction Alzheimer's disease*infection was found, one-way ANOVA was performed to delineate interaction hierarchy. Correlations between the grey and white matter were assessed for each inflammatory marker; based on the normality of the data, Pearson's (parametric) or Spearman's (non-parametric) test was applied. For the CD3+ T cells, Fisher's exact test was used for comparisons between subgroups with respect to the presence of the cells between group in the parenchyma or perivascular spaces in the grey or white matter. ELISA, MSD assay and qPCR: Mann-Whitney U-test was used for comparisons between $\mathrm{AD}$ - and $\mathrm{AD}+$ groups. Data were presented as median with interquartile range (IQR). All analyses were performed with SPSS software (version 24, IBM). $P$ values less than 0.05 for intergroup comparisons and 0.01 for correlations were considered statistically significant. Graphs were prepared with GraphPad Prism software (version 6, La Jolla, CA) and figures with Photoshop CS6 (version $13.0 \times 64$, Adobe).

\section{Results}

\section{Neuropathology}

To investigate whether systemic infection modifies key neuropathological features of $\mathrm{AD}$, we performed immunohistochemistry to compare $A \beta$ and ptau loads between the four groups, and ELISA to compare pre- and post-synaptic proteins in the two Alzheimer's groups. Systemic infection did not change $A \beta$ or ptau loads in either control or Alzheimer's patients. However, as expected, $\mathrm{AD}$ was associated with increased $\mathrm{A} \beta(p<0.001)$ and ptau $(p<0.001)$ compared to controls, irrespective of systemic infection (Table 2). Similarly, systemic infection did not affect the concentration of SYP or PSD95, or the ratio between these proteins, in $\mathrm{AD}(\mathrm{AD}+\mathrm{vs} . \mathrm{AD}$-; Table 3).

\section{Neuroinflammatory environment}

To assess the effect of systemic infection on the neuroinflammatory environment in AD, we used the MSD platform to measure the levels of IFN $\gamma$, IL1 $\beta$, IL2, IL4, IL6, IL8, IL10, IL12p70, IL13, TNF $\alpha$, IL1 $\alpha$, IL5, IL7, IL12/ IL23p40, IL15, IL16, IL17A, GM-CSF, TNF $\beta$ and VEGF in $\mathrm{AD}-$ and $\mathrm{AD}+$ groups. Significant differences in $\mathrm{AD}+$ cases were as follows: an increase in pro-inflammatory IL6 (1.5-fold, $p=0.047)$ and a decrease in cytokines IL5 (2.0-fold, $p=0.007$ ), IL7 (2.6-fold, $p=0.002$ ), IL12/IL23p40 (2.3-fold, $p=0.001$ ), IL15 (1.6-fold, $p=0.008)$, IL16 (2.4-fold, $p<0.001)$ and IL17A (2.4-fold, $p<0.001)$ (Table 4).

To investigate the role of systemic infection further in Alzheimer's cases, we used TaqMan qPCR to compare the fold difference in mRNA levels between $\mathrm{AD}+$ and 
Table 2 Quantification of the neuropathological changes. Amyloid (A) $\beta$ and hyperphosphorylated (p)tau loads (\%) in control and Alzheimer's disease cases detected by immunohistochemistry

\begin{tabular}{lllllll}
\hline Protein load (\%) & Ctrl- & Ctrl+ & AD- & AD+ & Mean difference $(95 \%$ Cl) & $P$ value \\
\hline A $\beta$ load & $2.66 \pm 3.38$ & $2.97 \pm 3.91$ & $7.49 \pm 3.37$ & $6.46 \pm 2.95$ & $4.15(2.82,5.48)$ & $<0.001$ \\
pTau & $0.01 \pm 0.20$ & $0.04 \pm 0.11$ & $2.20 \pm 3.52$ & $2.02 \pm 2.20$ & $2.09(1.18,2.98)$ & $<0.001$ \\
\hline
\end{tabular}

Values are mean $\pm \mathrm{SD} ; p$ value by 2 -way ANOVA test; significant $p$ value in italic

$C$ trl neurologically/cognitively normal controls, $A D$ Alzheimer's disease cases, - died without infection, + died with infection, $S D$ standard deviation, $C I$ confidence interval

AD- cases for cytokines and cytokine receptors (IL1b, IL4R, IL6, IL10, IFNg, TNF, TGFb1), enzymes (ARG1, COX2, NOS2), receptors (CD86, CD163, CD206, TREM2,) and the anti-inflammatory marker CHI3L1 (Chitinase 3-Like 1), relative to GAPDH mRNA. An increase in $I L 4 R$ (2-fold, $p=0.004$ ) and CHI3L1 (2.2-fold, $p=0.012$ ) mRNA was detected in $\mathrm{AD}+$ compared to $\mathrm{AD}$ - (Fig. 1).

\section{Microglia}

Several markers associated with specific microglial functions were investigated by immunohistochemistry in grey and white matter. These included: Iba1, a marker of microglial motility [50, 51]; CD68, a lysosomal/endosomal-associated transmembrane glycoprotein associated with phagocytosis [44, 57]; HLA-DR, necessary for antigen-presentation and involved in the non-self-recognition [44, 63]; and CCR2, a microglial chemokine receptor involved in mononuclear phagocyte infiltration in mouse brain $[21,22]$. FcyRs, as central effectors of immunoglobulin (Ig)G-mediated immune responses [48] were examined using CD64 (FcyRI), a high-affinity activating receptor [67]; CD32a (FcyRIIa) and CD16 (FcyRIII), both low-affinity activating receptors [48]; and CD32b (FcyRIIb) a low affinity inhibitory receptor [28]. In view of the qPCR findings, we also examined the anti-inflammatory proteins CHI3L1 and IL4R $[8,12]$.

Immunohistochemistry showed the following main cell-types expressing these proteins: antibodies to Iba1, CD68, HLA-DR, CD64 and CD16 immunolabelled microglia and perivascular macrophages; CD32a was also present in some neurons; CHI3L1 was detectable mainly in microglia as well as CCR2, as expected. CD32b, the only inhibitory $\mathrm{F} C \gamma \mathrm{R}$, and IL4R were expressed in neurons, with IL4R

Table 3 Quantification of the neuropathological changes. Synaptic proteins synaptophysin (SYP) and PSD-95 in Alzheimer's disease cases revealed by ELISA ( $\mu \mathrm{g} / \mathrm{ml})$

\begin{tabular}{llll}
\hline Protein concentration $(\mu \mathrm{g} / \mathrm{ml})$ & AD- & AD + & $P$ value \\
\hline SYP & $1.06(0.71,1.74)$ & $1.39(0.74,2.46)$ & 0.242 \\
PSD-95 & $1.95(0.10,3.35)$ & $1.92(1.04,2.48)$ & 0.374 \\
SYP/PSD-95 & $0.54(0.34,1.15)$ & $0.76(0.40,1.50)$ & 0.269 \\
\hline
\end{tabular}

Values are median \pm IQR; $p$ value by Mann-Whitney test SYP Synaptophysin, $A D$ Alzheimer's disease cases, - died without systemic infection, + died with systemic infection, IQR interquartile range antibody labelling tangles and neuropil threads in the Alzheimer's cases (Fig. 2, Additional file 1: Table S1).

Quantification of the immunolabelling (Table 5) in the grey matter indicated that: (i) CD68 $(p=0.026)$, CD64 $(p=0.002)$, CHI3L1 $(p=0.016)$, IL4R $(p=0.005)$ and CCR2 $(p=0.010)$ loads were increased in AD irrespective of systemic infection; and (ii) CD16 load was affected by both $\mathrm{AD}$ and systemic infection $(p=0.027)$ such that CD16 expression was lower in AD with systemic infection $(\mathrm{AD}+)$ compared to $\mathrm{AD}$ without systemic infection (AD-). In the white matter, CD32a was decreased by AD $(p=0.030)$ independent of systemic infection. Both CD68 $(p=0.015)$ and CD64 $(p=0.017)$ were affected by systemic infection in AD, with decreased CD68 and increased CD64 loads in AD+ vs. AD-. The other inflammatory markers were not modified by either AD or systemic infection.

We then explored the possible relationship between grey and white matter neuroinflammatory markers in the different subgroups to assess whether some of the markers were associated with the presence of systemic infection (Table 6). We found a grey-white matter correlation for HLA-DR, CD32b, CD16 and CHI3L1 regardless of subgroup. Grey-white matter correlation for Iba1 was found only in controls (Ctrl- and Ctrl+); grey-white matter correlation for CD68 and CCR2 was limited to brains affected by $\mathrm{AD}(\mathrm{AD}$ - and $\mathrm{AD}+)$. Interestingly, the grey-white matter correlation for $\mathrm{CD} 64$ was restricted to brains from donors with systemic infection. (i.e. present in both $\mathrm{Ctrl}+$ and $\mathrm{AD}+$ ).

\section{T lymphocytes}

We used immunohistochemistry for the pan-T cell marker CD3 [9] to investigate the relationship between systemic infection and $\mathrm{T}$ cell recruitment into the perivascular compartment and brain parenchyma in the grey and white matter. Systemic infection influenced T cells recruitment, with fewer cases displaying $\mathrm{T}$ cells in $\mathrm{AD}+\mathrm{vs}$. $\mathrm{AD}$ - (grey matter: blood vessels, $p=0.039$; white matter: blood vessels, $p=0.042$; parenchyma, $p=0.003$ ). In the absence of systemic infection, we confirm the presence of sparse T cells in AD brain [59] (Fig. 3).

\section{Vascular damage}

To investigate whether the neuroinflammatory changes after systemic infection might reflect vascular damage, 
Table 4 Comparison of inflammatory proteins in Alzheimer's cases detected by V-PLEX Meso Scale Discovery Multiplex Assays

\begin{tabular}{|c|c|c|c|c|}
\hline & AD- & $\mathrm{AD}+$ & $P$ value & Fold change \\
\hline \multicolumn{5}{|c|}{ Pro-inflammatory Panel 1 (pg/ml) } \\
\hline IFN $Y$ & $0.18(0.00,0.87)$ & $0.00(0.00,0.63)$ & 0.266 & \\
\hline IL1 $\beta$ & $0.00(0.00,0.65)$ & $0.36(0.00,0.95)$ & 0.097 & \\
\hline IL2 & $0.32(0.16,0.56)$ & $0.24(0.00,0.51)$ & 0.393 & \\
\hline IL4 & $0.33(0.27,045)$ & $0.33(0.25,0.40)$ & 0.834 & \\
\hline IL6 & $2.74(1.48,4.35)$ & $4.09(2.14,11.45)$ & 0.047 & 1.5 \\
\hline IL8 & $15.35(9.77,31.44)$ & $17.44(11.46,41.99)$ & 0.242 & \\
\hline IL10 & $0.05(0.00,0.21)$ & $0.08(0.00,0.20)$ & 0.747 & \\
\hline IL12p70 & $1.60(1.25,2.21)$ & $1.81(1.17,2.06)$ & 0.736 & \\
\hline IL13 & $10.95(9.50,16.72)$ & $11.70(9.51,15.29)$ & 0.869 & \\
\hline TNFa & $0.49(0.37,0.69)$ & $0.57(0.23,0.72)$ & 0.874 & \\
\hline \multicolumn{5}{|c|}{ Cytokines Panel 1 (pg/ml) } \\
\hline IL1a & $0.67(0.00,2.42)$ & $0.46(0.00,2.64)$ & 0.781 & \\
\hline IL5 & $0.08(0.04,0.18)$ & $0.04(0.01,0.08)$ & 0.007 & -2.0 \\
\hline IL7 & $1.32(0.81,1.88)$ & $0.54(0.26,1.09)$ & 0.002 & -2.6 \\
\hline IL12/IL23p40 & $0.70(0.45,1.14)$ & $0.31(0.13,0.76)$ & 0.001 & -2.3 \\
\hline IL15 & $6.32(4.95,8.24)$ & $3.88(2.42,6.95)$ & 0.008 & -1.6 \\
\hline IL16 & $614.82(404-13,1031.83)$ & $261.12(151.69,468.25)$ & $<0.001$ & -2.4 \\
\hline IL17A & $4.57(3.53,5.04)$ & $1.90(1.05,4.03)$ & $<0.001$ & -2.4 \\
\hline GM-CSF & $0.70(0.03,0.14)$ & $0.04(0.00,0.14)$ & 0.463 & \\
\hline TNF $\beta$ & $0.00(0.00,0.05)$ & $0.00(0.00,0.02)$ & 0.561 & \\
\hline VEGF & $10.94(4.78,21.70)$ & $7.75(2.70,17.52)$ & 0.242 & \\
\hline
\end{tabular}

Values are median with IQR; $p$ value by Mann-Whitney test; significant $p$ values in italic

Fold change, $A D+$ vs. AD-

$A D$ Alzheimer's disease cases, - died without systemic infection, + died with systemic infection, IQR interquartile range

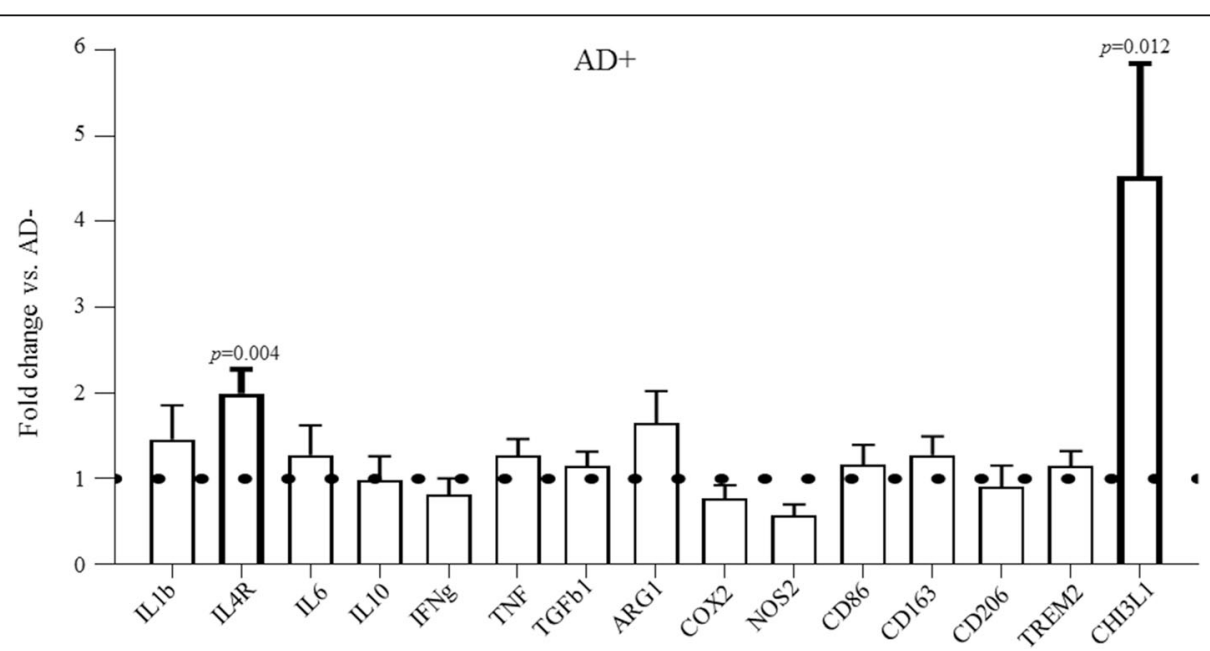

Fig. 1 Expression of inflammatory molecules in the presence of systemic infection in Alzheimer's disease using quantitative real-time PCR. The levels of indicated transcripts are normalised to GAPDH, and the mRNA Alzheimer's disease without systemic infection (AD-) levels are arbitrary set as 1. The bar graph shows the fold difference in mRNA of inflammatory markers and indicates significant increased anti-inflammatory gene transcripts CHI3LI ( $p=0.012)$ and IL4R ( $p=0.04)$ in Alzheimer's disease with (AD+) compared to without systemic infection (AD-) 


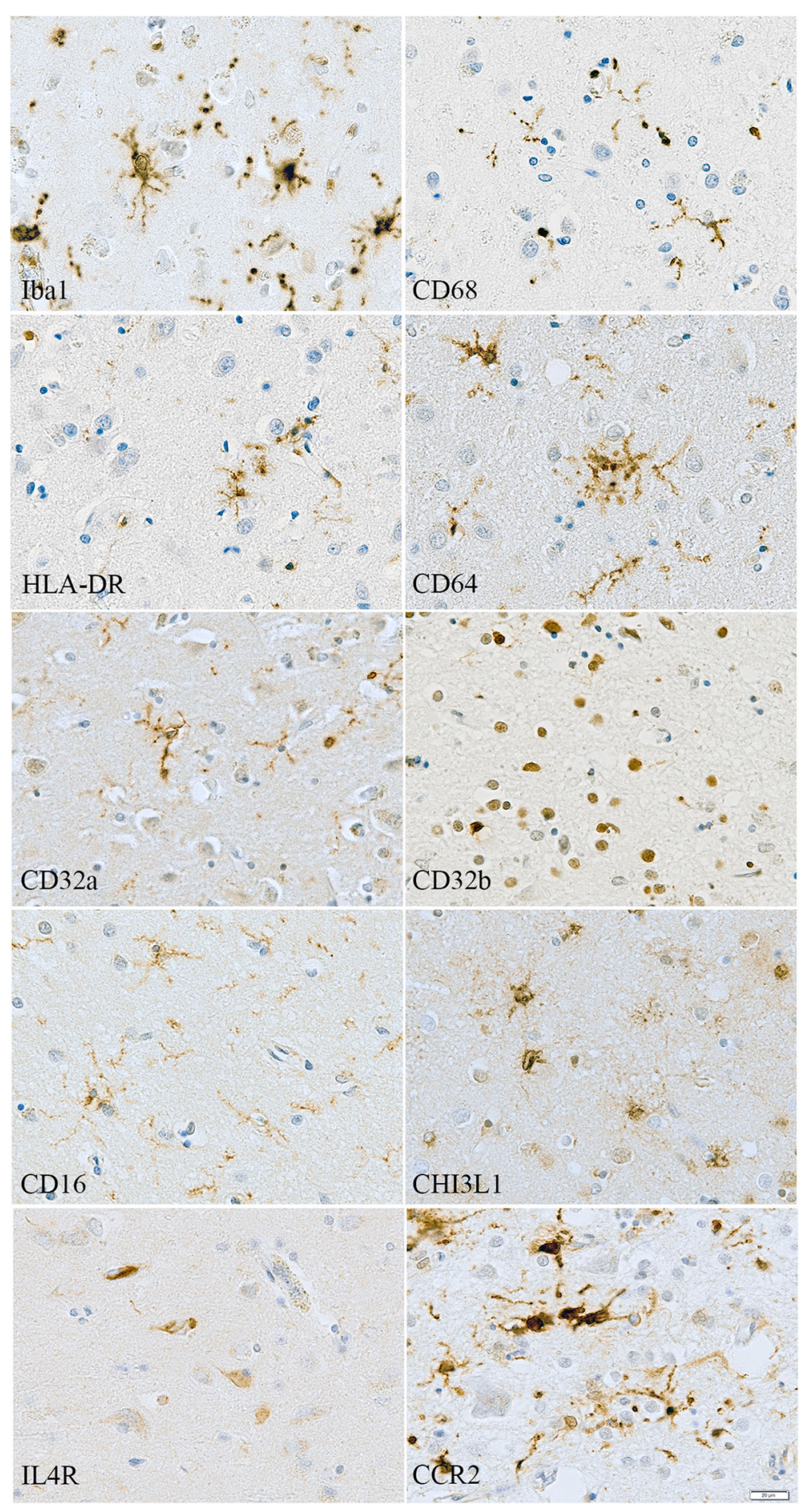

Fig. 2 Illustration of the immunostaining obtained with the different inflammatory markers in Alzheimer's disease. Counterstaining: Haematoxylin, Scale bar $=20 \mu \mathrm{m}$

we used the MSD platform to compare the levels of CRP, ICAM1, SAA, and VCAM1 between AD+ and AD- brains. No significant differences were observed (Additional file 1: Table S3).

\section{Discussion}

Our aim was to examine whether terminal systemic infection modified AD pathology, synaptic proteins and neuroinflammation. We found that systemic infection 
Table 5 Comparison of the inflammatory protein loads (\%) in control and Alzheimer's cases

\begin{tabular}{|c|c|c|c|c|c|c|}
\hline & Ctrl- & $\mathrm{Ctrl}+$ & AD- & $\mathrm{AD}+$ & Mean difference $(95 \% \mathrm{Cl})$ & $P$ value \\
\hline \multicolumn{7}{|c|}{ Grey Matter } \\
\hline |ba1 & $1.63 \pm 0.88$ & $1.81 \pm 1.14$ & $1.31 \pm 0.75$ & $1.35 \pm 1.14$ & & ns \\
\hline $\operatorname{CD} 68^{\mathrm{a}}$ & $0.21 \pm 0.08$ & $0.25 \pm 0.05$ & $0.29 \pm 0.14$ & $0.28 \pm 0.14$ & $0.06(0.007,0.103)$ & 0.026 \\
\hline HLA-DR & $0.03 \pm 0.05$ & $0.04 \pm 0.07$ & $0.12 \pm 0.16$ & $0.11 \pm 0.27$ & & ns \\
\hline $\mathrm{CD} 64^{\mathrm{a}}$ & $2.01 \pm 0.85$ & $2.26 \pm 1.35$ & $3.16 \pm 1.57$ & $2.97 \pm 1.55$ & $0.93(0.36,1.45)$ & 0.002 \\
\hline CD32a & $0.43 \pm 0.33$ & $0.46 \pm 0.61$ & $0.45 \pm 0.58$ & $0.36 \pm 0.46$ & & ns \\
\hline$C D 32 b^{a}$ & $0.08 \pm 0.10$ & $0.10 \pm 0.10$ & $0.29 \pm 0.52$ & $0.42 \pm 1.00$ & $0.27(-0.001,0.54)$ & ns \\
\hline \multirow[t]{3}{*}{$\mathrm{CD} 16^{\mathrm{b}}$} & $0.35 \pm 0.39$ & $0.86 \pm 1.25$ & $0.98 \pm 0.90$ & $0.67 \pm 0.93$ & Ctrl+: $0.51(-0.07,1.08)$ & 0.084 \\
\hline & & & & & AD-: $0.62(0.13,1.12)$ & 0.014 \\
\hline & & & & & $A D+: 0.31(-0.15,0.78)$ & 0.179 \\
\hline $\mathrm{CHI} 3 \mathrm{~L} 1^{\mathrm{a}}$ & $0.24 \pm 0.22$ & $0.37 \pm 0.36$ & $0.57 \pm 0.62$ & $0.73 \pm 0.96$ & $0.34(0.07,0.62)$ & 0.016 \\
\hline $\mathrm{IL} 4 \mathrm{R}^{\mathrm{a}}$ & $0.09 \pm 0.08$ & $0.07 \pm 0.06$ & $0.23 \pm 0.33$ & $0.20 \pm 0.24$ & $0.14(0.04,0.23)$ & 0.005 \\
\hline $\mathrm{CCR} 2^{\mathrm{a}}$ & $0.12 \pm 0.14$ & $0.09 \pm 0.08$ & $0.74 \pm 1.49$ & $0.38 \pm 0.50$ & $0.46(0.11,0.80)$ & 0.010 \\
\hline \multicolumn{7}{|c|}{ White Matter } \\
\hline Iba1 & $1.46 \pm 1.03$ & $2.13 \pm 1.52$ & $1.27 \pm 1.02$ & $1.43 \pm 1.13$ & & ns \\
\hline \multirow[t]{3}{*}{$\mathrm{CD} 68^{\mathrm{b}}$} & $0.11 \pm 0.10$ & $0.23 \pm 0.17$ & $0.36 \pm 0.22$ & $0.28 \pm 0.24$ & Ctrl+: $0.12(-0.01,0.25)$ & 0.076 \\
\hline & & & & & AD-: $0.25(0.14,037)$ & $<0.001$ \\
\hline & & & & & $A D+: 0.17(0.06,0.27)$ & 0.003 \\
\hline HLA-DR & $0.05 \pm 0.08$ & $0.03 \pm 0.06$ & $0.15 \pm 0.24$ & $0.09 \pm 0.23$ & & ns \\
\hline \multirow[t]{3}{*}{$\mathrm{CD} 64^{\mathrm{b}}$} & $0.70 \pm 0.42$ & $1.95 \pm 1.46$ & $1.36 \pm 0.89$ & $1.65 \pm 1.02$ & Ctrl+: $1.25(0.63,1.87)$ & $<0.001$ \\
\hline & & & & & AD-: $0.66(0.12,1.2)$ & 0.017 \\
\hline & & & & & $A D+: 0.95(0.45,1.45)$ & $<0.001$ \\
\hline CD32a $a^{a}$ & $0.58 \pm 0.67$ & $0.48 \pm 0.52$ & $0.34 \pm 0.46$ & $0.27 \pm 0.37$ & $-0.23(-0.43,0.02)$ & 0.030 \\
\hline CD16 & $0.10 \pm 0.14$ & $0.31 \pm 0.51$ & $0.28 \pm 0.30$ & $0.23 \pm 0.49$ & & ns \\
\hline CHI3L1 & $0.23 \pm 0.26$ & $0.50 \pm 0.57$ & $0.69 \pm 0.73$ & $0.62 \pm 1.12$ & & ns \\
\hline CCR2 & $0.06 \pm 0.11$ & $0.12 \pm 0.13$ & $0.30 \pm 0.55$ & $0.18 \pm 0.46$ & & ns \\
\hline
\end{tabular}

Values are mean $\pm \mathrm{SD}$; significant $p$ value in italic

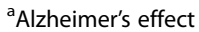

bne-way ANOVA test performed following significant Alzheimer's disease*infection interaction on the 2-way ANOVA analysis

$\mathrm{ns}$, non-significant following the 2-way ANOVA analysis

Ctrl neurologically/cognitively normal controls, AD Alzheimer's disease cases, - died without systemic infection, + died with systemic infection, $S D$ standard deviation, $\mathrm{Cl}$ confidence interval

was associated with downregulation of a range of pro-inflammatory markers and reduced T cell recruitment in the brain, but had no effect on $A \beta$, ptau, or synaptic proteins. In addition, systemic infection was associated with upregulated expression of the anti-inflammatory genes $I L 4 R$ and CHI3L1, in keeping with an immunosuppressive environment $[11,24]$.

Our study has limitations. Firstly, this was a retrospective observational study rather than a prospective experimental study. As an end-stage study, it was not possible to

Table 6 Correlations of neuroinflammation-related markers between the grey and the white matter in control and Alzheimer's cases

\begin{tabular}{|c|c|c|c|c|c|c|c|c|}
\hline Grey vs white matter & Iba1 & CD68 & HLA-DR & CD64 & CD32a & CD16 & CHI3L1 & CCR2 \\
\hline Ctrl- & $\rho=0.641^{* * *}$ & ns & $\rho=0.731^{* * *}$ & ns & $\rho=0.666^{* * *}$ & $\rho=0.893^{* * *}$ & $\rho=0.849^{* * *}$ & ns \\
\hline Ctrl+ & $r=0.724^{* *}$ & ns & $\rho=0.766^{* * *}$ & $r=0.763^{* * *}$ & $\rho=0.707^{* *}$ & $\rho=0.903^{* * *}$ & $\rho=0.768^{* * *}$ & ns \\
\hline$A D-$ & ns & $\rho=0.699^{* * *}$ & $\rho=0.917^{* * *}$ & ns & $\rho=0.956^{* * *}$ & $\rho=0.842^{* * *}$ & $\rho=0.821^{* * *}$ & $\rho=0.892^{* * *}$ \\
\hline$A D+$ & ns & $\rho=0.771^{* * *}$ & $\rho=0.925^{* * *}$ & $r=0.620^{* * *}$ & $\rho=0.866^{* * *}$ & $\rho=0.801^{* * *}$ & $\rho=0.896^{* * *}$ & $\rho=0.851^{* * *}$ \\
\hline
\end{tabular}

$\rho$, Spearman; $r$, Pearson; **p $\leq 0.01$; *** $p \leq 0.001$

Ctrl neurologically/cognitively normal controls, $A D$ Alzheimer's disease cases, - died without systemic infection, + died with systemic infection 


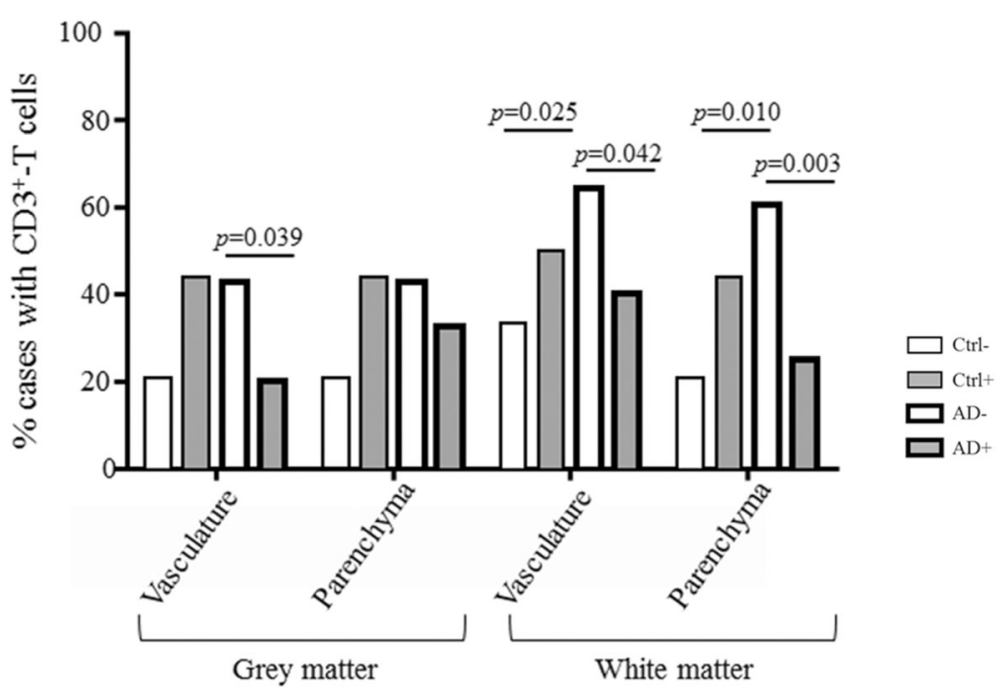

Fig. 3 Quantification of the CD3-positive T cells as percentage of cases presenting T cells in the blood vessels and/or the parenchyma in the grey and white matter, in the controls and Alzheimer's cases in the presence or absence of systemic infection at the time of death. The effect of Alzheimer's disease was detected in the white matter with increased T cells in the blood vessels $(p=0.025)$ and parenchyma $(p=0.010)$. An effect of infection was observed in Alzheimer's disease with fewer T cells in the Alzheimer's disease with systemic infection group in the grey matter blood vessels $(p=0.039)$, and the white matter (blood vessels: $p=0.042$; parenchyma: $p=0.003$ )

explore the temporal relationship between the different markers investigated, and thus the analysis was limited to assessment of the late-stage consequences of $\mathrm{AD}$ and systemic infection present at the time of death. Case selection with respect to the presence or absence of terminal infection relied on post-mortem findings and death certificates, and it is possible that the groups without systemic infection may have included some individuals with early, unrecognised infections. Conversely, in the groups with systemic infection, the infective process may have been too acute (i.e. short-lived) to have had major effects on brain inflammation. In addition, the lack of cytokine and protein measures in the control groups meant we could not provide information on the environment induced by systemic infection in the absence of Alzheimer's disease. Nevertheless, to our knowledge, this is the first neuropathological study of the effects of systemic infection on the neuroinflammatory environment and disease response in human AD. The major advantage of studying the human brain in this way is that it is a study of the disease itself rather than an experimental model of the disease. The novelty of our study resides in the combined quantitative assessment of multiple microglial markers with known functions, the neuroinflammatory environment and the neuropathological features of AD.

The neuroinflammatory environment in systemic infection In $\mathrm{AD}$, systemic infection was associated with increased IL6 and decreased levels of several pro-inflammatory cytokines. IL6 has been extensively studied in AD, in which there are elevated levels in the blood and brain
[39], associated with cognitive decline [35]. In the context of systemic infection in AD, raised serum IL6 was related to increased neuropsychiatric symptoms characteristic of sickness behaviour [29], consistent with our observation of a 1.5-fold elevation in IL6 in the brain in the Alzheimer's cases with systemic infection.

Systemic infection in AD was also associated with a reduction in several pro-inflammatory cytokines, mainly associated with the adaptive immune system. The few studies that have examined their role in AD have found: (i) elevated serum IL7 in early to mild AD [20]; (ii) elevated IL12p40 levels in the cerebrospinal fluid (CSF) of Alzheimer's patients [68]; (iii) administration of IL12p40 subunit blocker enhanced microglial phagocytosis and reduced inflammation in $A \beta$ transgenic mice [68]; (iv) raised IL15 levels in the CSF and serum of Alzheimer's patients correlated with severity of cognitive dysfunction [6, 58]; (v) increased peripheral IL16 in AD [19]; and overexpression of IL17A decreased soluble $A \beta$ levels without exacerbating neuroinflammation in a mouse model of $A \beta$ accumulation [73].

Our observed decrease in expression by more than $50 \%$ of several pro-inflammatory proteins with systemic infection should be considered in relation to the upregulation of the anti-inflammatory genes IL4R and CHI3L1. The role of IL4 in AD is uncertain: higher peripheral IL4 was found in mild cognitive impairment patients but not in dementia; increased disease severity was associated with lower levels of IL4 [36]. These findings may reflect a role for inflammation early in the disease process, consistent with genetic studies [33]. The significance of our 
observation of increased IL4R in AD with a similar immunolabelling pattern to that of ptau in $\mathrm{AD}$ brains is unclear. Loss of the normal immunoregulatory interaction between microglia and neurons, possibly through loss of the microglial regulatory protein CD200 [69], could lead microglia towards an anti-inflammatory profile, as suggested by previous studies [13, 34]. CHI3LI downregulates the cellular responses to pro-inflammatory cytokines TNF $\alpha$ and IL1 $\beta$ in vitro [40], implying an important role in regulating the inflammatory processes [37]. In AD, CHI3L1 was reported upregulated in the brain [13], and detected in the CSF of patients [72], and has been suggested as a biomarker for preclinical [14] and early $\mathrm{AD}[10,26]$. Interestingly, CHI3L1 raised levels were associated with markers of neurodegeneration in the preclinical stages of AD [2] and more specifically with tau-related neurodegeneration [3], perhaps related to IL4 expression. Indeed, BV2 mouse microglia treated with IL4 and IL13 upregulated the alternative activation genes [13], consistent with an association between IL4/IL4R and CHI3L1. IL4R and CHI3L1 seem usually to be expressed together and associated with an immunosuppressive environment.

\section{Microglia and T cells in systemic infection}

Systemic infection in Alzheimer's disease was associated with decreased CD68, CD16 (FcyRIII) and increased CD64 $(\mathrm{Fc} \gamma \mathrm{RI})$ proteins. The activating and inhibitory $\mathrm{F}_{\mathrm{c}} \gamma \mathrm{Rs}$, together generate a balanced immune response, associated with the production of a mixture of pro- and anti-inflammatory mediators $[42,46]$ and increased phagocytic activity [70]. FcyR expression was observed on microglia in normal and Alzheimer's human brain [53]; however, that study did not distinguish between the activating and inhibitory receptors. Modulation of microglial FcyRs was reported after acute systemic infection in chronic neurodegenerative disease in rodents: prion-infected mice challenged with a single intra-peritoneal lipopolysaccharide (LPS) injection upregulated FcyRIII and Fc $\gamma$ RIV, but not other microglial receptors including the inhibitory FcyRII [41]. Our data are consistent of an effect of systemic infection on FcyRs in AD and support a role for these receptors in the disease pathogenesis, but decrease in FcyRs in AD with systemic infection group again emphasizes the difference between the human disease and experimental models of neuroinflammation. The decreased CD16 and CD68, reflecting reduced phagocytic activity, is consistent with an immunosuppressive environment that might incapacitate the immune system so that it cannot respond appropriately to the disease. The increase in CD64, the Fc $\gamma \mathrm{R}$ with the highest affinity for IgG, in the white matter in the presence of systemic infection, may reflect the presence of more susceptible/primed or less immunosuppressive microglia in the white than in the grey matter, perhaps due the absence of pathology in the white matter, or differences in the blood-brain barrier.

The number of $\mathrm{T}$ Cells in $\mathrm{AD}[64,74]$ is diminished in the presence of systemic infection, as would be expected in the context of an immunosuppressive environment and with a dynamic communication between the systemic and brain immune systems. Measurement of CRP in serum is used clinically as a marker of systemic inflammatory processes but blood samples were not available for our cases. We performed the CRP measurement in brain tissue, but of note, the presence of systemic infection in the $\mathrm{AD}$ subjects was not reflected in. It is acknowledged that the cardinal signs of infection in the elderly may be absent or blunted in $20-30 \%$ of patients $[1,49]$. In the elderly, serum CRP begins to rise $6 \mathrm{~h}$ after a bacterial infection with the peak reached after $48 \mathrm{~h}$ and a half-life of $19 \mathrm{~h}$ [5]. Our CRP finding may be due to (i) absence of a rise in serum CRP in our patients, (ii) a dilution effect resulting from the much lower concentration of the protein in brain than serum or (iii) an inadequate survival time for a CRP response to have developed.

Interestingly, associations between microglial markers in the grey and white matter highlighted (i) Iba1 associated with control groups independently of systemic infection, maybe reflecting microglial motility, a function essential to healthy brain [44, 47]; (ii) CD68 (phagocytosis) and CCR2 (monocyte recruitment) as markers of neurodegeneration in $\mathrm{AD}$ independently of systemic infection; and (iii) CD64 as a potential marker of systemic infection whatever the disease status [44].

\section{The neuroinflammatory environment in AD}

We observed increased anti-inflammatory CHI3L1, IL4R, CD64 and CD32b proteins, potentially highlighting an anti-inflammatory maybe immunosuppressive environment in $\mathrm{AD}$ independent of systemic infection. Another study reported upregulation of alternative activation genes in experimental models and AD brains [13], and we previously showed in the Cognitive Function in Ageing (CFAS) cohort that CD64 was associated with dementia [44]. AD was also associated with increased phagocytosis (CD68), monocyte recruitment (CCR2), and immune responses mediated by CD64 receptor, mainly in the grey matter, in keeping with the distribution of Alzheimer's pathology and as previously reported in human and experimental studies [7, 23, 27, 32, 44].

\section{Systemic infection and Alzheimer's neuropathology}

Systemic infection did not affect $A \beta$, ptau or synaptic protein levels. This could be explained by (i) a saturation effect with the proteins having reached a plateau at late-stage disease [60]; (ii) a short interval between the onset of systemic infection and death not allowing time for the infection to modify protein levels via an altered 
neuroinflammatory environment; (iii) the immunosuppressive environment already present in $\mathrm{AD}$ and enhanced with systemic infection; or (iv) the absence of a relationship between the two events and these proteins.

\section{Conclusion}

In conclusion, our study suggests that end-stage $A D$ is associated with an anti-inflammatory (i.e. reducing or counteracting inflammation) brain environment, potentially immunosuppressive in the context of systemic infection. This underlines the difference between human disease and experimental models, that latter suggesting that a pro-inflammatory environment with enhanced neuronal loss is driven by systemic infection, and the assumption that sickness behaviour associated with raised peripheral TNF $\alpha$ and accelerated cognitive decline is due to an enhanced cerebral inflammation. Factors that could contribute to the difference in immune responses include the specific-pathogen-free environment in which the experimental animals are bred (unlike the human patients, who have been subjected to a lifetime of infections), and the experimental design. Indeed, a recent study in mice demonstrated that repeated peripheral LPS injections modified microglia and induced immune tolerance within the brain [71]. Based on the current knowledge, we suggest that early in the development of $\mathrm{AD}$, microglia primed by systemic infection respond to the disease in a detrimental manner (i.e. causing sickness behaviour, neuronal loss, increased pathology), but that over time, repeated systemic infections may induce an immunosuppressive environment within the brain so that towards the end-stage of $\mathrm{AD}$, there is marked downregulation of microglial inflammation, with equally deleterious consequences as evidenced by the accelerated cognitive decline [30].

\section{Additional file}

Additional file 1: Table S1. Characteristics of the primary antibodies, immunohistochemistry conditions and expression of the immunolabelling. Table S2. Primers and probes used for TaqMan qPCR (human sequences). Table S3. Comparison of vascular proteins in Alzheimer's cases detected by V-PLEX Meso Scale Discovery Multiplex Assays. (PDF 51 kb)

\section{Abbreviations}

ARG: Arginine; $A \beta$ : Amyloid- $\beta$; CCR: CC chemokine receptor; CHI3L1: Chitinase 3-Like 1; CNS: Central nervous system; COX: Cyclooxygenase; CRP: $C$ reactive protein; CSF: Cerebrospinal fluid; ELISA: Enzyme-linked immunosorbent assay; GAPDH: Glyceraldehyde 3-phosphate dehydrogenase; GM-CSF: Granulocyte macrophage colony-stimulating factor; HLA: Human leukocyte complex; HRP: Horseradish peroxidase; Iba1: Ionized calcium-binding adaptor molecule 1; ICAM: Intercellular adhesion molecule; IFN: Interferon; IL: Interleukin; LPS: Lipopolysaccharide; MCl: Mild cognitive impairment; MMSE: Mini-mental state examination; MSD: MesoScale Discovery; NOS: Nitrous oxide system; NSE: Neuron specific enolase; PET: Positron emission tomography;

PSD: Postsynaptic density; ptau: Hyperphosphorylated tau; SAA: Serum amyloid A; SYP: Synaptophysin; TGF: Transforming growth factor; TNF: Tumour necrosis factor; TREM: Triggering receptor expressed on myeloid cells; TSPO: 18-kDA translocator protein; VCAM: Vascular cell adhesion protein; VEGF: Vascular endothelial growth factor

\section{Acknowledgements}

We would like to thank the different brain banks and their managers for providing the tissue for this study. This includes: (i) Dr. Laura Palmer at the South West Brain Dementia Brain Bank (SWDBB) which is supported by BRACE (Bristol Research into Alzheimer's and Care of the Elderly), Brains for Dementia Research and the Medical Research Council; (ii) Jennifer Hay and the NHS Greater Glasgow and Clyde Trust as part of the UK Brain Archive Information Network (BRAIN UK) which is funded by the Medical Research Council and Brain Tumour Research. Multiples sclerosis samples were supplied by Dr. Djordje Gveric from the Parkinson's UK Brain Bank funded by Parkinson's UK, a charity registered in England and Wales (258197) and in Scotland (SC037554).

We thank Prof V. Hugh Perry from the Centre for Biological Sciences, University of Southampton, for his comments on the manuscript and Dr. Laurie C.K. Lau at Clinical and Experimental Sciences for his help with the MesoScale methodology. We acknowledge the Histochemistry Research Unit and the Biomedical Imaging Unit of the Faculty of Medicine, University of Southampton that facilitated tissue processing, staining and analysis.

\section{Funding}

This work was funded by the Alzheimer's Research UK (grant ARUK-PG2012-8).

\section{Availability of data and materials}

The data used and/or analysed during the current study are available from the corresponding author on reasonable request.

\section{Authors' contributions}

SR, YMAH, MS, WV and JW immunolabelled the 108 cases for the different inflammatory and neuropathological proteins and performed quantification. SR and DS performed the multiplex assays and SR the GPCR experiments. HMT provided the ELISA data on synapses. SR collected all the data and with DB analysed and interpreted them. SL and WS provided the cases and anonymised clinical notes. SH provided assistance with the statistical analyses. $\mathrm{CH}$ advised on the clinical relevance of the findings. JARN and DB conceived and designed the study and DB wrote the manuscript. All authors read and approved the final manuscript.

\section{Ethics approval}

Ethical approval was provided by: the South West Dementia Brain Bank (Research Ethics Committee South West Central Bristol, reference 08/H0106/ $28+5$ ) and BRAIN UK (Research Ethics Committee South Central Hampshire $B$, reference 14/SC/0098) for the controls and AD cases, and by the Multiple Sclerosis Society of Great Britain and Northern Ireland and Parkinson's UK (reference 08/MRE09/31 + 5) for frozen tissue used as controls for the MSD and $\mathrm{GPCR}$ protocols.

\section{Consent for publication}

Not applicable

\section{Competing interests}

The authors declare that they have no competing interests.

\section{Publisher's Note}

Springer Nature remains neutral with regard to jurisdictional claims in published maps and institutional affiliations.

\footnotetext{
Author details

${ }^{1}$ Clinical Neurosciences, Clinical and Experimental Sciences Academic Unit, Faculty of Medicine, University of Southampton, Southampton, UK. ${ }^{2}$ Dementia Research Group, University of Bristol Medical School, Learning \& Research, Southmead Hospital, Bristol, UK. ${ }^{3}$ Public Health Sciences and Medical Statistics, Faculty of Medicine, University of Southampton, Southampton, UK. ${ }^{4}$ Memory Assessment and Research Centre, Moorgreen Hospital, Southampton, UK. ${ }^{5}$ Department of Neuropathology, Queen Elizabeth University Hospital, Glasgow, UK. Institute of Neuroscience and Psychology, University of Glasgow, Glasgow, UK. ${ }^{7}$ Department of Cellular Pathology, University Hospital Southampton NHS Foundation Trust, Southampton, UK.
} 


\section{Received: 30 August 2018 Accepted: 30 August 2018}

\section{Published online: 07 September 2018}

\section{References}

1. Ahkee S, Srinath L, Ramirez J (1997) Community-acquired pneumonia in the elderly: association of mortality with lack of fever and leukocytosis. South Med J 90:296-298

2. Alcolea D, Martinez-Lage P, Sanchez-Juan P, Olazaran J, Antunez C, lzagirre A, Ecay-Torres M, Estanga A, Clerigue M, Guisasola MC et al (2015) Amyloid precursor protein metabolism and inflammation markers in preclinical Alzheimer disease. Neurology 85:626-633

3. Alcolea D, Vilaplana E, Pegueroles J, Montal V, Sanchez-Juan P, GonzalezSuarez A, Pozueta A, Rodriguez-Rodriguez E, Bartres-Faz D, Vidal-Pineiro D et al (2015) Relationship between cortical thickness and cerebrospinal fluid YKL-40 in predementia stages of Alzheimer's disease. Neurobiol Aging 36:2018-2023

4. Barton AJ, Pearson RC, Najlerahim A, Harrison PJ (1993) Pre- and postmortem influences on brain RNA. J Neurochem 61:1-11

5. Bertsch T, Triebel J, Bollheimer C, Christ M, Sieber C, Fassbender K, Heppner HJ (2015) C-reactive protein and the acute phase reaction in geriatric patients. Z Gerontol Geriatr 48:595-600

6. Bishnoi RJ, Palmer RF, Royall DR (2015) Serum interleukin (IL)-15 as a biomarker of Alzheimer's disease. PLoS One 10:e0117282

7. Boche D, Nicoll JA (2013) Neuroinflammation in ageing and in neurodegenerative disease. Neuropathol Appl Neurobiol 39:1-2

8. Boche D, Perry VH, Nicoll JA (2013) Activation patterns of microglia and their identification in the human brain. Neuropathol Appl Neurobiol 39:3-18

9. Chetty R, Gatter K (1994) CD3: structure, function, and role of immunostaining in clinical practice. J Pathol 173:303-307

10. Choi J, Lee HW, Suk K (2011) Plasma level of chitinase 3-like 1 protein increases in patients with early Alzheimer's disease. J Neurol 258:2181-2185

11. Cohen N, Shani O, Raz Y, Sharon Y, Hoffman D, Abramovitz L, Erez N (2017) Fibroblasts drive an immunosuppressive and growth-promoting microenvironment in breast cancer via secretion of Chitinase 3-like 1. Oncogene 36:4457-4468

12. Colton CA (2009) Heterogeneity of microglial activation in the innate immune response in the brain. J Neurolmmune Pharmacol 4:399-418

13. Colton CA, Mott RT, Sharpe H, Xu Q, Van Nostrand WE, Vitek MP (2006) Expression profiles for macrophage alternative activation genes in $A D$ and in mouse models of AD. J Neuroinflammation 3:27-39

14. Craig-Schapiro R, Perrin RJ, Roe CM, Xiong C, Carter D, Cairns NJ, Mintun MA, Peskind ER, Li G, al GDR (2010) YKL-40: a novel prognostic fluid biomarker for preclinical Alzheimer's disease. Biol Psychiatry 68:903-912

15. Cunningham C, Campion S, Lunnon K, Murray CL, Woods JF, Deacon RM, Rawlins JN, Perry VH (2009) Systemic inflammation induces acute behavioral and cognitive changes and accelerates neurodegenerative disease. Biol Psychiatry 65:304-312

16. Cunningham C, Campion S, Teeling J, Felton L, Perry VH (2007) The sickness behaviour and CNS inflammatory mediator profile induced by systemic challenge of mice with synthetic double-stranded RNA (poly l:C). Brain Behav Immun 21:490-502

17. Dantzer R, Bluthe RM, Gheusi G, Cremona S, Laye S, Parnet P, Kelley KW (1998) Molecular basis of sickness behavior. Ann N Y Acad Sci 856:132-138

18. Dantzer R, Kelley KW (2007) Twenty years of research on cytokine-induced sickness behavior. Brain Behav Immun 21:153-160

19. Di Rosa M, Dell'Ombra N, Zambito AM, Malaguarnera M, Nicoletti F, Malaguarnera L (2006) Chitotriosidase and inflammatory mediator levels in Alzheimer's disease and cerebrovascular dementia. Eur J Neurosci 23:2648-2656

20. Edwards M, Balldin VH, Hall J, O'Bryant S (2014) Combining select neuropsychological assessment with blood-based biomarkers to detect mild Alzheimer's disease: a molecular neuropsychology approach. J Alzheimers Dis 42:635-640

21. El Khoury J, Toft M, Hickman SE, Means TK, Terada K, Geula C, Luster AD (2007) Ccr2 deficiency impairs microglial accumulation and accelerates progression of Alzheimer-like disease. Nat Med 13:432-438

22. Gomez-Nicola D, Boche D (2015) Post-mortem analysis of neuroinflammatory changes in human Alzheimer's disease. Alzheimers Res Ther 7:42-50

23. Gomez-Nicola D, Schetters ST, Perry VH (2014) Differential role of CCR2 in the dynamics of microglia and perivascular macrophages during prion disease. Glia 62:1041-1052

24. Gordon S, Martinez FO (2010) Alternative activation of macrophages: mechanism and functions. Immunity 32:593-604
25. Gosselin D, Skola D, Coufal NG, Holtman IR, Schlachetzki JCM, Sajti E, Jaeger BN, O'Connor C, Fitzpatrick C, Pasillas MP et al (2017) An environmentdependent transcriptional network specifies human microglia identity. Science 356:1248

26. Hellwig K, Kvartsberg H, Portelius E, Andreasson U, Oberstein TJ, Lewczuk P, Blennow K, Kornhuber J, Maler JM, Zetterberg H et al (2015) Neurogranin and YKL-40: independent markers of synaptic degeneration and neuroinflammation in Alzheimer's disease. Alzheimers Res Ther 7:74

27. Heneka MT, Golenbock DT, Latz E (2015) Innate immunity in Alzheimer's disease. Nat Immunol 16:229-236

28. Hogarth PM, Pietersz GA (2012) Fc receptor-targeted therapies for the treatment of inflammation, cancer and beyond. Nat Rev Drug Discov 11: 311-331. https://doi.org/10.1038/nrd2909

29. Holmes C, Cunningham C, Zotova E, Culliford D, Perry VH (2011) Proinflammatory cytokines, sickness behavior, and Alzheimer disease. Neurology 77:212-218

30. Holmes C, Cunningham C, Zotova E, Woolford J, Dean C, Kerr S, Culliford D, Perry VH (2009) Systemic inflammation and disease progression in Alzheimer disease. Neurology 73:768-774

31. Hyman BT, Phelps CH, Beach TG, Bigio EH, Cairns NJ, Carrillo MC, Dickson DW, Duyckaerts C, Frosch MP, al ME (2012) National Institute on AgingAlzheimer's Association guidelines for the neuropathologic assessment of Alzheimer's disease. Alzheimers Dement 8:1-13

32. Ishizuka K, Kimura T, Igata-yi R, Katsuragi S, Takamatsu J, Miyakawa T (1997) Identification of monocyte chemoattractant protein-1 in senile plaques and reactive microglia of Alzheimer's disease. Psychiatry Clin Neurosci 51:135-138

33. Jones L, Holmans PA, Hamshere ML, Harold D, Moskvina V, Ivanov D, Pocklington A, Abraham R, Hollingworth P, Sims R et al (2010) Genetic evidence implicates the immune system and cholesterol metabolism in the aetiology of Alzheimer's disease. PLoS One 5:e13950

34. Kan MJ, Lee JE, Wilson JG, Everhart AL, Brown CM, Hoofnagle AN, Jansen M, Vitek MP, Gunn MD, Colton CA (2015) Arginine deprivation and immune suppression in a mouse model of Alzheimer's disease. J Neurosci 35:5969-5982

35. Kim YS, Lee KJ, Kim H (2017) Serum tumour necrosis factor-alpha and interleukin-6 levels in Alzheimer's disease and mild cognitive impairment. Psychogeriatrics 17:224-230

36. King E, O'Brien JT, Donaghy P, Morris C, Barnett N, Olsen K, Martin-Ruiz C, Taylor JP, Thomas AJ (2018) Peripheral inflammation in prodromal Alzheimer's and Lewy body dementias. J Neurol Neurosurg Psychiatry 89:339-345

37. Lee CG, Da Silva CA, Dela Cruz CS, Ahangari F, Ma B, Kang MJ, He CH, Takyar S, Elias JA (2011) Role of chitin and chitinase/chitinase-like proteins in inflammation, tissue remodeling, and injury. Annu Rev Physiol 73:479-501

38. Lemstra AW, Groen in't Woud JC, Hoozemans JJ, van Haastert ES, Rozemuller AJ, Eikelenboom P, van Gool WA (2007) Microglia activation in sepsis: a case-control study. J Neuroinflammation 4:4

39. Licastro F, Grimaldi LM, Bonafe M, Martina C, Olivieri F, Cavallone L, Giovanietti S, Masliah E, Franceschi C (2003) Interleukin-6 gene alleles affect the risk of Alzheimer's disease and levels of the cytokine in blood and brain Neurobiol Aging 24:921-926

40. Ling $H$, Recklies AD (2004) The chitinase 3-like protein human cartilage glycoprotein 39 inhibits cellular responses to the inflammatory cytokines interleukin-1 and tumour necrosis factor-alpha. Biochem J 380:651-659

41. Lunnon K, Teeling JL, Tutt AL, Cragg MS, Glennie MJ, Perry VH (2011) Systemic inflammation modulates fc receptor expression on microglia during chronic neurodegeneration. J Immunol 186:7215-7224

42. Mantovani A, Sica A, Sozzani S, Allavena P, Vecchi A, Locati M (2004) The chemokine system in diverse forms of macrophage activation and polarization. Trends Immunol 25:677-686

43. Martinez-Nunez RT, Louafi F, Sanchez-Elsner T (2011) The interleukin 13 (IL-13) pathway in human macrophages is modulated by microRNA-155 via direct targeting of interleukin 13 receptor alpha1 (IL13Ralpha1). J Biol Chem 286: 1786-1794

44. Minett T, Classey J, Matthews FE, Fahrenhold M, Taga M, Brayne C, Ince PG, Nicoll JA, Boche D (2016) Microglial immunophenotype in dementia with Alzheimer's pathology. J Neuroinflammation 13:135-145

45. Mirra SS, Heyman A, McKeel D, Sumi SM, Crain BJ, Brownlee LM, Vogel FS, Hughes JP, van Belle G, Berg L (1991) The consortium to establish a registry for Alzheimer's disease (CERAD). Part II. Standardization of the neuropathologic assessment of Alzheimer's disease. Neurology 41:479-486

46. Mosser DM, Edwards JP (2008) Exploring the full spectrum of macrophage activation. Nat Rev Immunol 8:958-969 
47. Nimmerjahn A, Kirchhoff F, Helmchen F (2005) Resting microglial cells are highly dynamic surveillants of brain parenchyma in vivo. Science 308:1314-1318

48. Nimmerjahn F, Gordan S, Lux A (2015) FcgammaR dependent mechanisms of cytotoxic, agonistic, and neutralizing antibody activities. Trends Immunol 36:325-336 D

49. Norman DC (2000) Fever in the elderly. Clin Infect Dis 31:148-151

50. Ohsawa K, Imai Y, Kanazawa H, Sasaki Y, Kohsaka S (2000) Involvement of Iba1 in membrane ruffling and phagocytosis of macrophages/microglia. J Cell Sci 113(Pt 17):3073-3084

51. Ohsawa K, Imai Y, Sasaki Y, Kohsaka S (2004) Microglia/macrophage-specific protein Iba1 binds to fimbrin and enhances its actin-bundling activity. J Neurochem 88:844-856

52. Palmer JC, Barker R, Kehoe PG, Love S (2012) Endothelin-1 is elevated in Alzheimer's disease and upregulated by amyloid-beta. J Alzheimers Dis 29:853-861

53. Peress NS, Fleit HB, Perillo E, Kuljis R, Pezzullo C (1993) Identification of fC gamma RI, II and III on normal human brain ramified microglia and on microglia in senile plaques in Alzheimer's disease. J Neuroimmunol 48:71-79

54. Perry VH, Cunningham C, Holmes C (2007) Systemic infections and inflammation affect chronic neurodegeneration. Nat Rev Immunol 7:161-167

55. Perry $\mathrm{VH}$, Holmes $\mathrm{C}$ (2014) Microglial priming in neurodegenerative disease. Nat Rev Neurol 10:217-224

56. Preece $P$, Cairns NJ (2003) Quantifying mRNA in postmortem human brain: influence of gender, age at death, postmortem interval, brain $\mathrm{pH}$, agonal state and inter-lobe mRNA variance. Mol Brain Res 118:60-71

57. Rabinowitz SS, Gordon S (1991) Macrosialin, a macrophage-restricted membrane sialoprotein differentially glycosylated in response to inflammatory stimuli. J Exp Med 174:827-836

58. Rentzos M, Zoga M, Paraskevas GP, Kapaki E, Rombos A, Nikolaou C, Tsoutsou A, Vassilopoulos D (2006) IL-15 is elevated in cerebrospinal fluid of patients with Alzheimer's disease and frontotemporal dementia. J Geriatr Psychiatry Neurol 19:114-117

59. Schroder K, Sweet MJ, Hume DA (2006) Signal integration between IFNgamma and TLR signalling pathways in macrophages. Immunobiology 211:511-524

60. Serrano-Pozo A, Mielke ML, Gomez-Isla T, Betensky RA, Growdon JH, Frosch MP, Hyman BT (2011) Reactive glia not only associates with plaques but also parallels tangles in Alzheimer's disease. Am J Pathol 179:1373-1384

61. Sharshar T, Annane D, de la Grandmaison GL, Brouland JP, Hopkinson NS, Francoise G (2004) The neuropathology of septic shock. Brain Pathol 14:21-33

62. Sinclair LI, Tayler HM, Love S (2015) Synaptic protein levels altered in vascular dementia. Neuropathol Appl Neurobiol 41:533-543

63. Styren SD, Civin WH, Rogers J (1990) Molecular, cellular, and pathologic characterization of HLA-DR immunoreactivity in normal elderly and Alzheimer's disease brain. Exp Neurol 110:93-104

64. Togo T, Akiyama H, Iseki E, Kondo H, Ikeda K, Kato M, Oda T, Tsuchiya K, Kosaka K (2002) Occurrence of T cells in the brain of Alzheimer's disease and other neurological diseases. J Neuroimmunol 124:83-92

65. Uchikado H, Akiyama H, Kondo H, Ikeda K, Tsuchiya K, Kato M, Oda T, Togo $T$, Iseki E, Kosaka K (2004) Activation of vascular endothelial cells and perivascular cells by systemic inflammation-an immunohistochemical study of postmortem human brain tissues. Acta Neuropathol 107:341-351

66. van Helmond Z, Boche D, Nicoll J, Holmes C, Neal J, Love S (2009) Oligomeric a beta levels following a beta(42) immunisation. Neuropathol Appl Neurobiol 35:25-25

67. Vogelpoel LT, Baeten DL, de Jong EC, den Dunnen J (2015) Control of cytokine production by human fc gamma receptors: implications for pathogen defense and autoimmunity. Front Immunol 6:79

68. Vom Berg J, Prokop S, Miller KR, Obst J, Kalin RE, Lopategui-Cabezas I, Wegner A, Mair F, Schipke CG, Peters O et al (2012) Inhibition of IL-12/IL-23 signaling reduces Alzheimer's disease-like pathology and cognitive decline. Nat Med 18:1812-1819

69. Walker DG, Dalsing-Hernandez JE, Campbell NA, Lue LF (2009) Decreased expression of CD200 and CD200 receptor in Alzheimer's disease: a potential mechanism leading to chronic inflammation. Exp Neurol 215:5-19

70. Walker DG, Lue LF (2015) Immune phenotypes of microglia in human neurodegenerative disease: challenges to detecting microglial polarization in human brains. Alzheimers Res Ther 7:56

71. Wendeln AC, Degenhardt K, Kaurani L, Gertig M, Ulas T, Jain G, Wagner J, Hasler LM, Wild K, Skodras A et al (2018) Innate immune memory in the brain shapes neurological disease hallmarks. Nature 556:332-338
72. Wennstrom M, Surova Y, Hall S, Nilsson C, Minthon L, Hansson O, Nielsen HM (2015) The inflammatory marker YKL-40 is elevated in cerebrospinal fluid from patients with Alzheimer's but not Parkinson's disease or dementia with Lewy bodies. PLoS One 10:e0135458

73. Yang J, Kou J, Lalonde R, Fukuchi KI (2017) Intracranial IL-17A overexpression decreases cerebral amyloid angiopathy by upregulation of ABCA1 in an animal model of Alzheimer's disease. Brain Behav Immun 65:262-273

74. Zotova E, Bharambe V, Cheaveau M, Morgan W, Holmes C, Harris S, Neal JW Love S, Nicoll JA, Boche D (2013) Inflammatory components in human Alzheimer's disease and after active amyloid-beta42 immunization. Brain 136:2677-2696

\section{Ready to submit your research? Choose BMC and benefit from:}

- fast, convenient online submission

- thorough peer review by experienced researchers in your field

- rapid publication on acceptance

- support for research data, including large and complex data types

- gold Open Access which fosters wider collaboration and increased citations

- maximum visibility for your research: over $100 \mathrm{M}$ website views per year

At BMC, research is always in progress.

Learn more biomedcentral.com/submissions 